\title{
HUBUNGAN ANTARA FAKTOR SOSIODEMOGRAFI DENGAN POTENSI KEJADIAN DEPRESI MATERNAL PADA IBU HAMIL DI PUSKESMAS PAMPANG KOTA MAKASSAR
}

\author{
Muzakkir $^{1}$, Azniah $^{2}$ Sitti aminah ${ }^{3}$ \\ ${ }^{1}$ STIKES Nani Hasanuddin Makassar \\ ${ }^{2}$ STIKES Nani Hasanuddin Makassar \\ ${ }^{3}$ STIKES Nani Hasanuddin Makassar
}

(Alamat Respondensi: viraveynnihal@gmail.com/081343427035)

\begin{abstract}
ABSTRAK
Kehamilan merupakan suatu proses dari kehidupan seorang wanita, dengan adanya proses kehamilan yang terjadi pada diri seorang wanita akan menyebabkan beberapa perubahan. Ada tiga faktor yang mempengaruhi kehamilan yaitu faktor fisik, faktor psikologis dan faktor sosial, budaya dan ekonomi. Kondisi kehamilan yang berisiko juga dapat mengakibatkan terganggunya kondisi psikologis. Hal yang cukup berbahaya ialah ibu hamil berisiko rentan mengalami depresi. Tujuan penelitian adalah untuk mengetahui hubungan antara faktor sosiodemografi dengan potensi kejadian depresi maternal pada ibu hamil di Puskesmas Pampang Kota Makassar. Penelitian ini menggunakan metode penelitian deskriptif analitik dengan pendekatan cross sectional study dan dilaksanakan di Puskesmas Pampang Kota Makassar pada tanggal 13 Desember 2018 sampai 17 Januari 2019. Populasi penelitian adalah seluruh ibu hamil yang berada di wilayah kerja Puskesmas Pampang sejumlah $596 \mathrm{lbu}$ hamil selama periode 2018. Metode pengambilan sampel yang digunakan adalah kluster random dengan jumlah sampel sebanyak 221 ibu. Hasil penelitian ini didapatkan bahwa hubungan antara usia ibu $(p=0,699)$, pendidikan ibu $(p=0,569)$, pekerjaan ibu $(p=1,000)$, dan pendapatan keluarga $(p=1,000)$ dengan potensi kejadian depresi maternal pada ibu hamil di Puskesmas Pampang Kota Makassar. Kesimpulan penelitian ini adalah tidak ada hubungan antara usia, pendidikan, pekerjaan, dan pendapatan keluarga dengan potensi kejadian depresi maternal pada ibu hamil di Puskesmas Pampang Kota Makassar.
\end{abstract}

\section{Kata kunci: Faktor Sosiodemografi, Potensi Kejadian Depresi Maternal}

\section{PENDAHULUAN}

Kehamilan merupakan suatu proses dari kehidupan seorang wanita, dengan adanya proses kehamilan yang terjadi pada diri seorang wanita akan menyebabkan beberapa perubahan. Ada tiga faktor yang mempengaruhi kehamilan yaitu faktor fisik, faktor psikologis dan faktor sosial, budaya dan ekonomi (Mandang, dkk., 2016). Kondisi kehamilan yang berisiko juga dapat mengakibatkan terganggunya kondisi psikologis. Hal yang cukup berbahaya ialah ibu hamil berisiko rentan mengalami depresi (Fauzy \& Fourianalisyawati, 2016).

Perempuan di seluruh dunia berhak menikmati kesehatan yang setara. Ketika mereka menjadi ibu, kebutuhan kesehatan mereka harus ditangani dalam semua aspek. Tujuan Millennium Development Goals (MDG's) telah menyoroti pentingnya kesehatan ibu dan anak dan agenda pembangunan pasca 2015 dan The Commission on the Status of Women (2014), lebih lanjut menekankan pada kesetaraan gender dan pemberdayaan perempuan, sebuah arah strategis yang sangat didukung oleh WHO. Sekitar 20\% ibu di negara berpenghasilan rendah dan menengah menderita gangguan mental setelah melahirkan. Ini hampir dua kali lipat persentase dalam konteks pendapatan tinggi. Rencana WHO's Global Mental Health Action Plan 2013-2020 yang disahkan oleh World Health Assembly pada tahun 2013 merekomendasikan perawatan kesehatan mental dan sosial yang komprehensif, terpadu dan responsif serta penerapan strategi untuk promosi dan pencegahan dan merujuk pada kesehatan mental anak dan ibu yang terintegrasi (WHO, 2015).

Prevalensi kecemasan ibu pada periode antenatal dan postnatal diperkirakan diantara 221.974 wanita dari 34 negara. Hasil penelitian menunjukkan kecemasan di seluruh periode perinatal sangat lazim dan manfaat perhatian klinis mirip dengan yang diberikan kepada depresi perinatal. Tingkat prevalensi secara signifikan lebih tinggi di negara 
berpenghasilan rendah hingga menengah yang mungkin mengindikasikan pengaruh budaya. Paradigma Perkembangan Paradigma Kesehatan dan Penyakit menunjukkan bahwa kesehatan dan perkembangan manusia berasal dari kehidupan awal sejak konsepsi hingga anak usia dini. Selama periode ini, interaksi antara faktor ibu dan faktor lingkungan program perkembangan janin dan anak melalui perubahan fisiologis yang memiliki konsekuensi jangka panjang pada kesehatan nanti (Dennis, et. al, 2017).

Berdasarkan data dari Puskesmas Pampang Kota Makassar, menunjukkan bahwa jumlah kunjungan ibu hamil pada tahun 2016 sebanyak 864 ibu hamil, meningkat pada tahun 2017 sebanyak 893 ibu hamil, sedangkan jumlah kunjungan ibu hamil dari bulan Januari sampai September 2018 sebanyak 596 ibu (Data Sekunder Puskesmas Pampang Kota Makassar, 2018). Berdasarkan data dari sekian banyak jumlah ibu hamil di Puskesmas, terdapat beberapa ibu hamil yang mempunyai potensi depresi maternal, salah satu penyebab dapat dipengaruhi oleh faktor internal yaitu faktor sosiodemografi ibu hamil. Menurut Syam, et al (2017) beberapa variabel yang termasuk sosio-demografi, seperti usia ibu, paritas, latar belakang pendidikan suami, pekerjaan ibu, struktur keluarga, seks neonatal, dan pengetahuan.

Berdasarkan uraian tersebut, maka peneliti merasa perlu untuk melakukan penelitian tentang Hubungan Antara Faktor Sosiodemografi dengan Potensi Kejadian Depresi Maternal pada lbu Hamil di Puskesmas Pampang Kota Makassar.

\section{BAHAN DAN METODE}

Lokasi, populasi, dan sampel

Penelitian ini dilakukan di Puskesmas

Pampang Kota Makassar pada tanggal 13 Desember 2018 sampai 17 Januari 2019. Populasi penelitian adalah seluruh ibu hamil yang berada di wilayah kerja Puskesmas Pampang sejumlah 596 lbu hamil selama periode 2018 dengan sampel didapatkan 221 ibu hamil. Kriteria Inklusi:

1. Ibu hamil mulai dari trimester I-III.

2. Bersedia untuk menjadi responden.

3. Bermukim permanen di wilayah penelitian.

4. Follow-up (tidak mengganti nomor kontak selama satu tahun ke depan).

\section{Pengumpulan data}

1. Data primer

Pengumpulan data primer diperoleh dengan menggunakan kuesioner yang telah disediakan oleh peneliti.
2. Data sekunder

Pengumpulan data sekunder diperoleh dari buku register Puskesmas Pampang Kota Makassar.

\section{Pengolahan Data}

1. Editing

Hasil angket yang dikumpulkan melalui kuesioner perlu disunting (edit) terlebih dahulu. Kalau tenyata masih ada data atau informasi yang tidak lengkap, dan tidak mungkin dilakukan wawancara ulang, maka kuesioner tersebut dikeluarkan.

2. Coding sheet

Lembaran atau kartu kode berisi nomor responden, dan nomor pertanyaan.

3. Data entry

Mengisi kolom lembar sesuai dengan jawaban masing-masing pertanyaan.

4. Tabulasi

Membuat tabel data, sesuai dengan tujuan penelitian atau yang diinginkan oleh peneliti (Notoatmodjo, 2014).

Analisa data

1. Analisis univariat

Analisa univariat pada umumnya dalam analisis ini menghasilkan distribusi frekuensi dan persentase dari tiap variabel.

2. Analisis bivariat

Analisis bivariat yang dilakukan terhadap dua variabel yang diduga berhubungan atau berkorelasi (Notoatmodjo, 2014).

\section{HASIL PENELITIAN}

1. Analisis univariat

Tabel 1. Analisis Distribusi Karakteristik Responden di Wilayah Kerja Puskesmas Pampang $(\mathrm{n}=221)$

\begin{tabular}{|c|c|c|}
\hline Karakteristik & $\mathrm{n}$ & $\%$ \\
\hline Umur & & \\
<20 tahun & 25 & 11,3 \\
20-35 tahun & 167 & 76,5 \\
$>35$ tahun & 29 & 13,2 \\
\hline Pendidikan & & \\
Tinggi & 39 & 17,6 \\
Menengah & 140 & 63,4 \\
Dasar & 42 & 19,0 \\
\hline Potensi kejadian & & \\
depresi maternal & & \\
Kemungkinan & 171 & 77,4 \\
depresi & 50 & 22,6 \\
Normal &
\end{tabular}

Berdasarkan tabel diatas menunjukkan bahwa umur responden terbanyak adalah 20-35 tahun yaitu sebanyak 167 responden (76,5\%). Pendidikan responden terbanyak adalah 
menengah yaitu sebanyak 140 responden $(63,4 \%)$. Pekerjaan responden terbanyak adalah tidak bekerja yaitu sebanyak 189 responden (85,5\%). Pendapatan responden terbanyak adalah $>$ UMR yaitu sebanyak 126 responden (57,0\%). Potensi kejadian depresi maternal responden terbanyak adalah kemungkinan depresi yaitu sebanyak 171 responden $(77,4 \%)$.

2. Analisis bivariat

Tabel 2. Analisis Hubungan Antara Usia Ibu dengan Potensi Kejadian Depresi Maternal pada Ibu Hamil di Wilayah Kerja Puskesmas Pampang ( $\mathrm{n}=221)$

\begin{tabular}{|c|c|c|c|c|c|c|}
\hline \multirow{3}{*}{ Umur } & \multicolumn{4}{|c|}{$\begin{array}{l}\text { Potensi kejadian } \\
\text { depresi maternal }\end{array}$} & \multirow{2}{*}{\multicolumn{2}{|c|}{ Total }} \\
\hline & \multicolumn{2}{|c|}{ Depresi } & \multicolumn{2}{|c|}{ Normal } & & \\
\hline & $\mathrm{n}$ & $\%$ & $\mathrm{n}$ & $\%$ & $\mathrm{n}$ & $\%$ \\
\hline$<20$ tahun & 21 & 84,0 & 4 & 16,0 & 25 & 100,0 \\
\hline $\begin{array}{l}20-35 \\
\text { tahun }\end{array}$ & 128 & 76,6 & 39 & 23,4 & 167 & 100,0 \\
\hline$>35$ tahun & 22 & 75,9 & 7 & 24,1 & 29 & 100,0 \\
\hline Total & 171 & 77,4 & 50 & 22,6 & 221 & 100,0 \\
\hline & & $p=0$, & & & & \\
\hline
\end{tabular}

Berdasarkan hasil uji statistik dengan Chi-square diperoleh nilai $p=0,699$. Karena nilai $p>\alpha=0,05$, maka hipotesis nol diterima dan hipotesis alternatif ditolak. Interpretasi tidak ada hubungan antara usia ibu dengan potensi kejadian depresi maternal pada ibu hamil di Puskesmas Pampang Kota Makassar.

Tabel 3. Analisis Hubungan Antara Pendidikan Ibu dengan Potensi Kejadian Depresi Maternal pada lbu Hamil di Wilayah Kerja Puskesmas Pampang $(\mathrm{n}=221)$

\begin{tabular}{|c|c|c|c|c|c|c|}
\hline \multirow{3}{*}{ Pendidikan } & \multicolumn{3}{|c|}{$\begin{array}{l}\text { Potensi kejadian } \\
\text { depresi maternal }\end{array}$} & \multicolumn{3}{c|}{ Total } \\
\cline { 2 - 6 } & Depresi & Normal & \multicolumn{2}{c|}{} \\
\cline { 2 - 6 } & $\mathrm{n}$ & $\%$ & $\mathrm{n}$ & $\%$ & $\mathrm{n}$ & $\%$ \\
\hline Tinggi & 29 & 74,4 & 10 & 25,6 & 39 & 100,0 \\
Menengah & 107 & 76,4 & 33 & 23,6 & 140 & 100,0 \\
Dasar & 35 & 83,3 & 7 & 16,7 & 42 & 100,0 \\
\hline Total & 171 & 77,4 & 50 & 22,6 & 221 & 100,0 \\
\hline \multicolumn{6}{|c|}{$p=0,569$} \\
\hline
\end{tabular}

Berdasarkan hasil uji statistik dengan Chi-square diperoleh nilai $p=0,569$. Karena nilai $p>\alpha=0,05$, maka hipotesis nol diterima dan hipotesis alternatif ditolak. Interpretasi tidak ada hubungan antara pendidikan ibu dengan potensi kejadian depresi maternal pada ibu hamil di Puskesmas Pampang Kota Makassar.

\section{PEMBAHASAN}

1. Hubungan antara usia ibu dengan potensi kejadian depresi maternal pada ibu hamil

Berdasarkan penelitian ini telah dilaksanakan di Puskesmas Pampang Kota Makassar menunjukkan bahwa hasil uji statistik dengan Chi-square diperoleh tidak ada hubungan antara usia ibu dengan potensi kejadian depresi maternal pada ibu hamil di Puskesmas Pampang Kota Makassar. Hal ini dapat dipengaruhi oleh paritas ibu.

Hasil penelitian ini sejalan dengan penelitian yang telah dilakukan oleh Rahmitha (2017), mengemukakan bahwa tidak ada hubungan tingkat kecemasan berdasarkan usia pada ibu hamil primigravida trimester ketiga. Kecemasan berat yang dialami oleh ibu hamil yang berusia muda $(<20$ tahun) dapat mempengaruhi lahan persepsi sehingga seseorang cenderung memusatkan perhatian pada sesuatu yang terindi, spesifik, dan tidak dapat berpikir tentang hal lain. Sedangkan, ibu hamil yang berusia cukup mengalami kecemasan ringan yang berhubungan dengan ketegangan dalam kehidupan sehari-hari dan menyebabkan peningkatan lahan persepsi.

Hasil penelitian ini berbeda dengan penelitian yang telah dilakukan oleh Rinata \& Andayani (2018), menunjukkan ada hubungan usia dengan kecemasan. Usia 20-35 tahun merupakan usia yang dianggap aman untuk menjalani kehamilan dan persalinan. Karena pada usia $<20$ tahun kondisi fisik terutama organ reproduksi dan psikologis belum 100\% siap menjalani masa kehamilan dan persalinan. Sedangkan kehamilan pada usia $>35$ tahun merupakan keadaan yang dikategorikan dalam resiko tinggi terhadap kelainan bawaan serta adanya penyulit selama masa kehamilan dan persalinan.

Umur berkaitan dengan kedewasaan atau maturitas seseorang. Kedewasaan adalah kedewasaan tehnis dalam melaksanakan tugas-tugas maupun kedewasaan psikologis. Menurut Siagian, 2001, semakin lanjut usia seseorang maka semakin meningkat pula kedewasaan tehnis maupun psikologisnya, serta menunjukkan kematangan jiwa. Umur semakin meningkatkan akan meningkatkan pula kebijakan kemampuan seseoramg dalam mengambil keputusan, berfikir rasional, mengendalikan emosi dan bertoleransi terhadap pandangan orang lain (Kurniadi, 2016). 
Menurut asumsi peneliti, tidak terdapat hubungan usia ibu dengan potensi kejadian depresi maternal pada ibu hamil secara statistik, tetapi secara klinis dapat dilihat bahwa ibu hamil yang berumur $<20$ tahun lebih kemungkinan mengalami depresi maternal dibandingkam ibu yang berumur 20-35 tahun dan $>35$ tahun. Jadi dapat disimpulkan bahwa semakin muda umur responden maka semakin tinggi kemungkinan potensi depresi maternal pada ibu hamil. Tidak adanya hubungan dalam penelitian ini juga dapat dipengaruhi oleh faktor paritas ibu. Ibu hamil dengan paritas primigravida akan cenderung lebih mengalami depresi karena ibu beranggapan kehamilan yang dijalaninya pengalaman pertama yang dihadapi, sehingga lebih mudah mengalami depresi selama kehamilan.

2. Hubungan antara pendidikan ibu dengan potensi kejadian depresi maternal pada ibu hamil

Berdasarkan penelitian ini telah dilaksanakan di Puskesmas Pampang Kota Makassar menunjukkan bahwa hasil uji statistik dengan Chi-square diperoleh tidak ada hubungan antara pendidikan ibu dengan potensi kejadian depresi maternal pada ibu hamil di Puskesmas Pampang Kota Makassar. Hal ini dapat dipengaruhi oleh kurangnya informasi mengenai kehamilan yang dimiliki ibu hamil.

Hasil penelitian ini sejalan dengan penelitian yang telah dilakukan oleh Said, dkk., (2015), menunjukkan tidak ada hubungan antara pendidikan dengan kecemasan ibu primigravida di Puskesmas Tuminting, kemungkinan disebabkan oleh faktor lain yaitu pendapatan yang telah diteliti oleh peneliti. Pendidikan dapat mempengaruhi kecemasan ibu hamil selama kehamilan, disebabkan pendidikan dapat mempengaruhi presepsi seseorang, cara berfikir dalam mengelola informasi dan mengambil keputusan. Semakin tinggi pendidikan seseorang maka akan semakin berkualitas pengetahuannya dan semakin matang intelektualnya.

Hasil penelitian ini berbeda dengan penelitian yang telah dilakukan oleh Rinata \& Andayani (2018), menunjukkan bahwa ada hubungan pendidikan dengan kecemasan. Tingkat pendidikan seseorang turut menentukan mudah tidaknya menyerap dan memahami pengetahuan tentang proses persalinan yang mereka peroleh, dengan demikian semakin bertambahnya usia kehamilan mendekati proses persalinan ibu dapat mempersiapkan psikologi yang matang sehingga dapat mengurangi beban fikiran ibu.

Wanita yang berpendidikan akan lebih terbuka terhadap ide baru dan perubahan untuk mendapatkan pelayanan kesehatan yang proposional karena manfaat pelayanan kesehatan akan mereka sadari sepenuhnya. Jenjang pendidikan adalah tahapan pendidikan yang ditetapkan berdasarkan tingkat perkembangan peserta didik, tujuan yang akan dicapai, dan kemampuan yang dikembangkan. Pendidikan di Indonesia mengenal tiga jenjang pendidikan, yaitu: pendidikan dasar (SD/MI dan SMP/MTs), pendidikan menengah (SMA/SMK) dan pendidikan tinggi yang mencakup program Diploma, Sarjana, Megister, Doktor dan Spesialis yang diselenggarakan oleh perguruan tinggi (Padila, 2017).

Menurut asumsi peneliti, tidak terdapat hubungan pendidikan ibu dengan potensi kejadian depresi maternal pada ibu hamil secara statistik, tetapi secara klinis dapat dilihat bahwa ibu berpendidikan dasar lebih kemungkinan mengalami depresi maternal dibandingkan ibu yang berpendidikan menemgah dam dasar. Jadi dapat disimpulkan bahwa semakin rendah pendidikan responden maka semakin tinggi kemungkinan potensi depresi maternal pada ibu hamil. Tidak adanya hubungan dalam penelitian ini juga dapat dipengaruhi oleh kurangnya informasi yang diterima ibu sehingga akan mempengaruhi kepercayaan diri ibu selama kehamilan. Ibu yang hamil akan merasa cemas karena kurang percaya diri dan takut akan keadaan yang akan terjadi apabila persalinan.

\section{KESIMPULAN}

1. Tidak ada hubungan antara usia ibu dengan potensi kejadian depresi maternal pada ibu hamil di Puskesmas Pampang Kota Makassar.

2. Tidak ada hubungan antara pendidikan ibu dengan potensi kejadian depresi maternal pada ibu hamil di Puskesmas Pampang Kota Makassar.

\section{SARAN}

1. Diharapkan ibu hamil untuk meningkatkan pengetahuan tentang kehamilan serta berkonsultasi dengan petugas kesehatan demi mengurangi potensi depresi maternal ibu hamil.

2. Diharapkan kepada keluarga untuk memberikan dukungan yang lebih kepada 
anggota yang hamil demi mencegah anggota keluarganya mengalami potensi depresi maternal.

3. Diharapkan kepada perawat bagian Poli KIA lebih mengembangkan pemahaman keperawatan dalam mengatasi potensi depresi maternal pada ibu hamil serta menjadikan bahan evaluasi bagi puskesmas untuk memaksimalkan komunikasi terapeutik yang dilakukan perawat.

\section{DAFTAR PUSTAKA}

Dennis, C., Hassani, K., \& Shiri, R. (2017). Prevalence of Antenatal and Postnatal Anxiety: Systematic Review and Meta-Analysis. The British Journal of Psychiatry.

Fauzy, R., \& Fourianalisyawati, E. (2016). Hubungan antara Depresi dengan Kualitas Hidup pada lbu Hamil Berisiko Tinggi. Jurnal Psikogenesis, Volume 4, No.2.

Husniawati, N., \& Fajriani. (2017). Hubungan Antara Karakteristik Ibu dan Dukungan Suami Terhadap Tingkat Kecemasan Ibu Hamil Trimester III Di Puskesmas Kecamatan Makasar. Jurnal IImiah Kesehatan, Volume 9 No.1.

Kurniadi, A. (2016). Manajemen Keperawatan dan Prospektifnya (Teori, Konsep dan Aplikasi). Jakarta: FKUI.

Mandang, J., Tombokan, S. J., \& Tando, N. M. (2016). Asuhan Kebidanan Kehamilan. Bogor: In Media.

Notoatmodjo, S. (2014). Metodologi Penelitian Kesehatan. Jakarta: PT. Rineka Cipta.

Padila. (2017). Keperawatan Maternitas. Yogyakarta: Nuha Medika.

Priyoto. (2014). Teori Sikap dan Perilaku dalam Kesehatan Dilengkapi dengan Contoh Kuesioner. Yogyakarta: Nuha Medika.

Rahmitha, N. (2017). Tingkat Kecemasan Pada lbu Hamil Primigravida Trimester Ketiga di Puskesmas Kecamatan Tamalanrea Makassar. Jurnal Program Studi Pendidikan Dokter.

Rinata, E., \& Andayani, G. A. (2018). Karakteristik lbu (Usia, Paritas, Pendidikan) dan Dukungan Keluarga dengan Kecemasan Ibu Hamil Trimester III. Jurnal IImiah IImu-ilmu Kesehatan, Vol 16 No 1.

Said, N., Kanine, E., \& Bidjuni, H. (2015). Hubungan Faktor Sosial Ekonomi dengan Kecemasan Ibu Primigravida di Puskesmas Tuminting. ejournal Keperawatan (e-Kp) Volume 3. Nomor 2.

Syam, A., Syafar, M., Amiruddin, R., Muzakkir, Darwis, Darmawan, S., et al. (2017). Early Breastfeeding Initiation: Impact of Socio-demographic, Knowledge and Social Support Factors. Pakistan Journal of Nutrition, Volume 16 (4).

Walyani, E. S. (2015). Asuhan Kebidanan pada Kehamilan. Yogyakarta: Pustaka Baru Press.

Wanda, A., Bidjuni, H., \& Kallo, V. (2014). Hubungan Karakteristik Ibu Hamil Trimester III dengan Tingkat Kecemasan dalam Menghadapi Persalinan di Poli Kia Puskesmas Tuminting. Jurnal Keperawatan Fakultas Kedokteran.

WHO. (2015). Thinking Healthy: A Manual for Psychosocial Management of Perinatal Depression (WHO Generic Feld-Trial Version 1.0). Geneva: World Health Organization. 